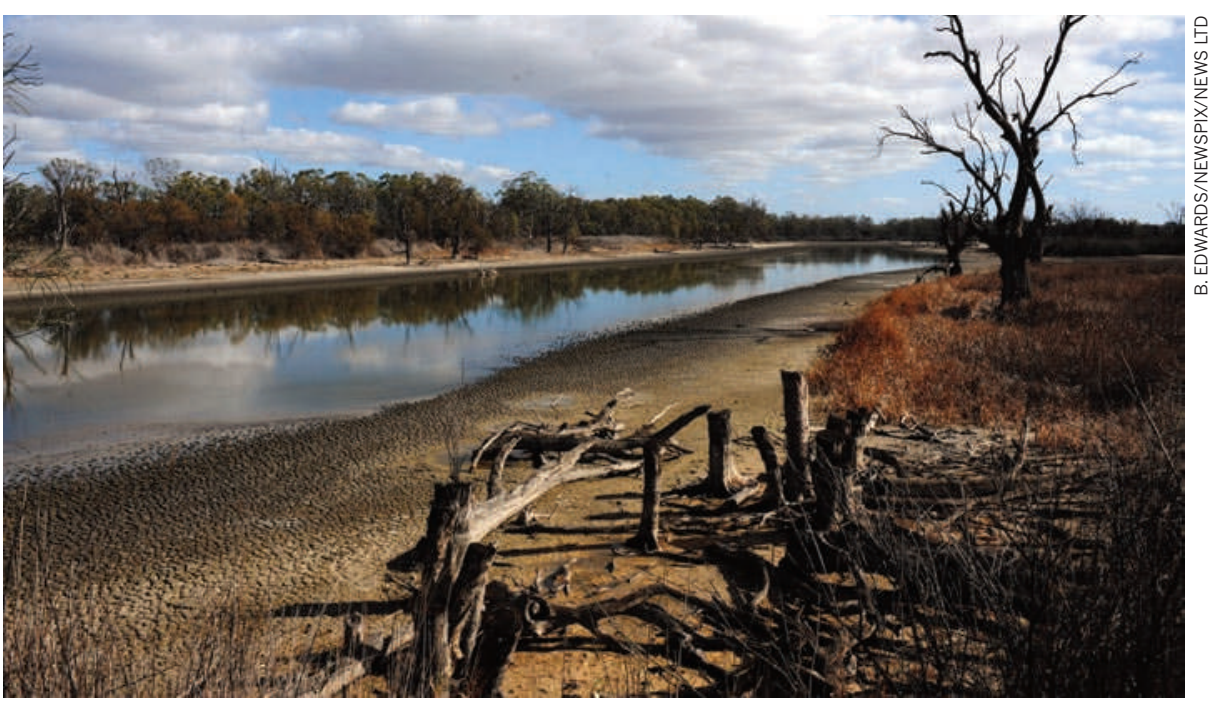

Restoration of Australia's drying Murray-Darling basin has caused a rift between farmers and scientists.

\title{
River chief resigns
}

\section{Plan to save Australian river system runs aground.}

\section{BY STEPHEN PINCOCK IN SYDNEY}

$\mathrm{T}$ The challenge of balancing human needs for water with those of the environment has come to a head in Australia's ailing Murray-Darling river system, where an ambitious plan to restore the ecosystem was thrown into turmoil on 7 December after the leader of the scheme resigned.

Michael Taylor, chairman of the governmentappointed Murray-Darling Basin Authority, announced he was stepping down just 2 months after releasing a draft plan for water management that prompted protests from the region's farmers, but which was largely backed by many of Australia’s environmental scientists.

Covering 1 million square kilometres in southeastern Australia, the Murray-Darling basin is a vital agricultural region, containing rich wetland habitats and around 50 endangered species of birds and mammals. But decades of poor water management and drought have left ecosystems in crisis and many farmers short of water.

Research by the Commonwealth Scientific and Industrial Research Organisation in 2007-08 revealed that water use in the basin had reduced average annual streamflow at the mouth of the Murray River by $61 \%$, which now fails to reach the sea $40 \%$ of the time. This has brought ecological problems such as increased salinity, algal blooms and the collapse of native fish and waterbird populations.

Successive state and national governments in Australia have struggled to manage the region's water resources. In October, the basin authority released a blueprint to address the problem by reducing the amount of water diverted for irrigation from the basin's 77,000 kilometres of rivers. The main recommendation - that 3,000-4,000 billion litres of water should be released from agricultural use each year and returned to the environment - triggered months of heated debate about the effect on farm communities.

The government asked Taylor to ensure the plan balanced ecological outcomes with the impact on jobs or other socioeconomic factors. But in his resignation statement, Taylor said he had received legal advice that the plan "cannot compromise the minimum level of water required to restore the system's environment on social or economic grounds". He urged the government to reconsider the plan's next phase.

Richard Kingsford, director of the Australian Wetlands and Rivers Centre at the University of New South Wales in Sydney, said that the resignation was "symptomatic of what a difficult process this is. It's true that a basin plan can't do everything."

Kingsford and 57 other environmental scientists recently released a statement saying that debate over the plan was too focused on shortterm economic pain rather than the long-term economic benefits of a healthy river system. $\mathrm{He}$ and his colleagues argue that the next version of the basin plan, due early next year, should use 3,000-4,000 billion litres as the minimum release volume. "Michael Taylor's resignation might provide for a new form of leadership to come in and take the issue on," Kingsford says.

The final plan for the Murray-Darling basin is due to be tabled in the Australian parliament at the end of 2011 following consultation with the public, state governments and ministers. 